\title{
Effect of hot air assisted infrared drying on drying characteristics and quality of rice bran pellets
}

\author{
Sahachart Sansak and Jiraporn Sripinyowanich Jongyingcharoen* \\ Department of Agricultural Engineering, Faculty of Engineering, King Mongkut's Institute of Technology Ladkrabang, Bangkok, \\ Thailand
}

\begin{abstract}
The objective of this study was to determine drying characteristics and quality of rice bran pellet subjected to hot air assisted infrared (HA-IR) drying at different levels of infrared (IR) intensity (750 - 3750 $\left.\mathrm{W} / \mathrm{m}^{2}\right)$ and air temperature $\left(40-80^{\circ} \mathrm{C}\right)$. The rice bran pellets were dried from 0.18 to $0.08 \mathrm{~g}$ water $/ \mathrm{g}$ dry matter. The maximum drying rate (DR) and drying time were in the ranges of $0.0030-0.0165 \mathrm{~g}$ water $/ \mathrm{g}$ dry matter $\min$ and $8-54 \mathrm{~min}$, respectively. Higher IR intensity and air temperature resulted in greater maximum DR and shorter drying time. The same trend was also observed for the effective moisture diffusivity $\left(D_{\text {eff }}\right)$ values which were between $0.3103 \times 10^{-7}$ and $2.7603 \times 10^{-7} \mathrm{~m}^{2} / \mathrm{s}$. As compared to the commercial reference sample of dried rice bran pellets, the products of this study had higher oil content and lower FFA content. The oil content was affected by IR intensity only while the FFA content was affected both by IR intensity and air temperature. HA-IR drying could improve drying characteristics of the rice bran pellets and produce better quality of the dried products.
\end{abstract}

\section{Introduction}

Rice bran is a by-product obtained during the process of rice milling. It is $8-10 \%$ of the whole grain weight and generally used for rice bran oil production. In the industrial level of rice bran oil production, the rice bran is subjected to steam cooking and extruding to be rice bran pellets. During this step, enzymatic degradation is delayed and porous structure of the rice bran is formed. However, the pellets are high in moisture content, at risk of lipid oxidation, and unsuitable for oil extraction. Typically, the pellets must be dried prior to oil extraction. Conventional drying method used for rice bran pellets is hot air drying, which takes long time and needs high temperature.

This research was focused on investigating an alternative drying technique to reduce moisture from the rice bran pellets. IR drying has been reviewed as a potential method for drying various agricultural products. Penetration of IR radiation provides more uniform heating than hot air as the radiation impinges and penetrates on material and then its energy is converted into heat [1]. In the field of paddy drying and rice bran stabilization, many researchers have reported a promising potential of IR heating in inactivating the lipase enzymes in rice bran $[1,2]$. The lipases are the main cause of the hydrolysis of neutral bran oil to free fatty acids (FFA), leading to the development of hydrolytic rancidity [3]. Application of HA-IR drying is reported to be advantage as it had best synergistic effect and saved drying time as compared to the hot air or IR drying alone $[4,5]$.
In the prior studies, advantages of IR heating have been clearly established for treatment of rice bran. However, the research on drying of rice bran pellets is lacked. Therefore, the objective of this study was to determine drying characteristics and quality of rice bran pellet undergoing HA-IR drying. Effects of IR intensity $\left(750-3750 \mathrm{~W} / \mathrm{m}^{2}\right)$ and hot air temperature $\left(40-80^{\circ} \mathrm{C}\right)$ on rice bran pellet drying were also investigated.

\section{Materials and methods}

\subsection{Sample preparation}

The rice bran pellets, prepared by steam cooking and extruding, were provided by CEO AGRI FOOD Co. Ltd., Singburi, Thailand. Its moisture content was $0.18 \mathrm{~g}$ water/g dry matter. It was packed in polypropylene ziplocked bags and kept in a refrigerator at $4-5^{\circ} \mathrm{C}$ prior to use. The sample was left at room temperature before running the experiments.

\subsection{Architecture of the hot air assisted infrared dryer}

The HA-IR dryer is presented in Fig. 1. A double-walled stainless steel drying chamber was cylindrical with a diameter and length of 30 and $60 \mathrm{~cm}$. Two infrared heaters of $800 \mathrm{~W}$ each were installed inside the chamber at the top. The heaters generated a surface temperature of $750^{\circ} \mathrm{C}$ with the peak wavelength of $3.1 \mathrm{~mm}$. An aluminum cover was placed over the heaters as an infrared reflector. The perforated stainless steel drying tray $\left(0.20 \times 0.40 \times 0.05 \mathrm{~m}^{3}\right)$ was fitted in the chamber with the distance from the heaters at $20 \mathrm{~cm}$. Fin heaters of 4

*Corresponding author: jiraporn.jo@kmitl.ac.th 
$\mathrm{kW}$ and a blower of $0.5 \mathrm{HP}$ were used for producing hot air. The hot air temperature was measured by thermocouples (type K, Lega model AK-01, Lega Coperation Co., Ltd., Bangkok, Thailand) and controlled by PID (Proportional-Integral-Derivative Controller) with an accuracy of $\pm 1^{\circ} \mathrm{C}$.

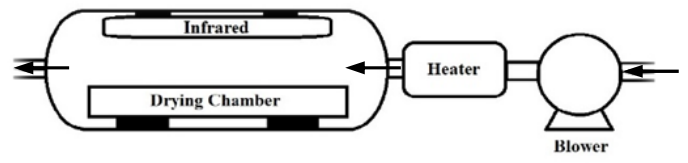

Fig. 1 A HA-IR dryer

\subsection{Experimental plan}

Full factorial experiment in complete randomized design was conducted for HA-IR drying of the rice bran pellets with the independent variables of infrared intensity (750, 2250 , and $\left.3750 \mathrm{~W} / \mathrm{m}^{2}\right)$ and hot air temperatures $(40,60$, $80^{\circ} \mathrm{C}$ ). From the preliminary experiment of this study, the levels of infrared intensity and hot air temperature higher than $3750 \mathrm{~W} / \mathrm{m}^{2}$ and $80^{\circ} \mathrm{C}$ caused the rice bran pellets to be burnt. Air velocity was fixed at $1 \mathrm{~m} / \mathrm{s}$. The rice bran pellets were placed in single layer on the drying tray and dried to the final moisture content of $0.08 \mathrm{~g}$ water/g dry matter. During drying, the sample was weighed at the predetermined intervals to measure its moisture content. Drying characteristics and $D_{\text {eff }}$ were determined as shown in 2.4 and 2.5. Quality of the dried product was also evaluated as shown in 2.6. Reference sample, the hot air dried rice bran pellets provided by CEO AGRI FOOD Co. Ltd., Singburi, Thailand, was also used for comparison purpose. The reference was the rice bran pellets dried using the commercial scale hot air dryer at the temperature of $140^{\circ} \mathrm{C}$ for $30 \mathrm{~min}$, which is the typical condition used by the company.

\subsection{Drying characteristic determination}

Moisture content was determined in a hot air oven at $105^{\circ} \mathrm{C}$ for $24 \mathrm{~h}$ [6]. The equation for calculation of the moisture content in dry basis is as follows:

$$
M=\frac{W_{w}-W_{d}}{W_{d}}
$$

where $M, W_{w}$, and $W_{d}$ are moisture content (g water/g dry matter), wet weight of the material $(\mathrm{g})$, and dry weight of the material $(\mathrm{g})$, respectively. below:

Moisture ratio (MR) and DR were calculated as

$$
\begin{gathered}
M R=\frac{M_{t}-M_{e}}{M_{i}-M_{e}} \\
D R=\frac{M_{t+d t}-M_{t}}{d t}
\end{gathered}
$$

where $M_{i}, M_{t}, M_{e}$, and $\mathrm{M}_{t+\mathrm{d} t}$ are moisture content ( $\mathrm{g}$ water/g dry matter) at initial, specific time, equilibrium, and $t+\mathrm{d} t$, respectively; and $t$ is drying time $(\mathrm{min}) . M_{e}$ can be assumed to be zero when drying at high temperature and for radiation drying [7].

\subsection{Calculation of effective moisture diffusivity}

To present the mechanism of moisture movement during drying, $\mathrm{D}_{\text {eff }}$ was calculated. The diffusion mechanism can be explained by Fick's second law based on shape of the material. Rice bran pellets are finite cylindrical. The general series of Fick's second law for a finite cylindrical object is given in Eq. (4) [8]. The first term equation was used for the solution of $\mathrm{D}_{\text {eff. }}$.

$$
M R=\frac{8}{\pi^{2}} \sum_{m=1}^{\infty} \frac{4}{\lambda_{m}^{2}} \exp \left(\frac{\lambda_{m}^{2} D_{e f f} t}{r_{0}^{2}}\right) \sum_{n=1}^{\infty} \frac{1}{(2 n-1)^{2}} \exp \left(\frac{-\pi^{2}(2 n+1)^{2} D_{e f f} t}{4 l}\right)
$$

where $D_{\text {eff }}$ is the effective diffusivity $\left(\mathrm{m}^{2} / \mathrm{s}\right) ; \lambda_{m}$ is the root of the Bessel function of the first kind of zero order; $\mathrm{R} 0$ is initial radius of the cylinder $(\mathrm{m})$; and 1 is half length of the cylinder $(\mathrm{m})$.

\subsection{Quailty evaluation}

\subsubsection{Oil content}

Oil content was determined using the solvent extraction, AACC method 30-10 [9]. $n$-hexane was used as the extraction solvent and after the extraction process, was removed using a rotary evaporator. The oil content was expressed as g oil/g dry matter.

\subsubsection{Free fatty acid}

FFA content was determined by AOCS official method Ca 5a-40 [10]. The rice bran oil extracted from 2.6.1 was dissolved in a mixture of ethanol and diethyl ether and titrated with a $\mathrm{KOH} /$ ethanol solution. The FFA content was calculated as oleic acid equivalent.

\subsection{Statistical analysis}

The experiments were triplicated. Mean and standard deviation were used to present the experimental results. Two-way ANOVA was used to analyse the data statistically. Duncan's multiple range test was used to determine the significance of differences between treatments at $95 \%$ confident interval.

\section{Results and discussion}

\subsection{Drying characteristics}

Representative drying curves and DR curves of HA-IR drying of rice bran pellets are shown in Figs. 2-5. Effects of air temperature and infrared intensity were considerable and only two DR periods i.e. the heating up and falling rate period were observed. Increased values of these two parameters resulted in enhanced DR and shortened drying time. As presented in Table 1, the highest maximum DR and the shortest drying time were obtained when using the highest IR intensity and air temperature of $3750 \mathrm{~W} / \mathrm{m}^{2}$ and $80^{\circ} \mathrm{C}$, respectively. It was also observed that the varied IR intensity used in this study had more crucial effect than the varied air temperature. The greater effect of the IR intensity over the air temperature was also observed by Ponkham [5] for HA-IR drying of ring shaped-pineapple at 1000-5000 $\mathrm{W} / \mathrm{m}^{2}$ and $40-60^{\circ} \mathrm{C}$. Particularly, when increasing the level of IR intensity from 2250 to $3750 \mathrm{~W} / \mathrm{m}^{2}$, the DR dramatically increased by about $0.009 \mathrm{~g}$ water/g dry matter'min at each constant level of the air temperature. 


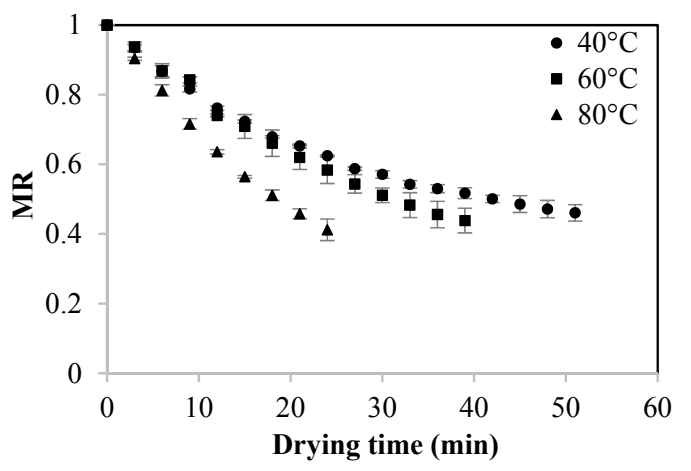

Fig. 2 Drying curves of HA-IR drying of the rice bran pellets at the IR intensity of $750 \mathrm{~W} / \mathrm{m}^{2}$.

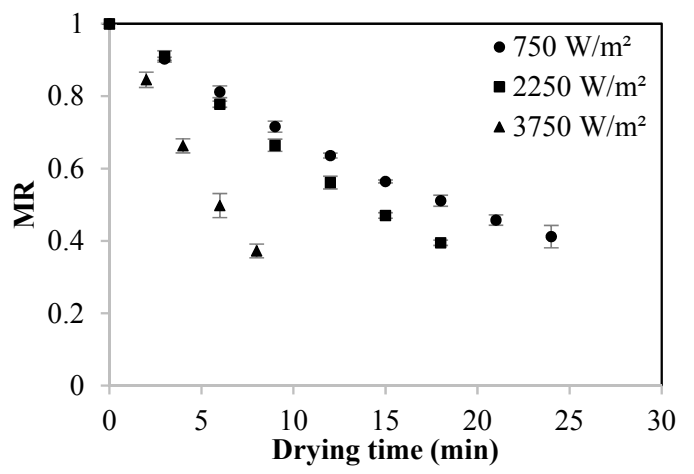

Fig. 3 Drying curves of HA-IR drying of the rice bran pellets at the air temperature of $80^{\circ} \mathrm{C}$.

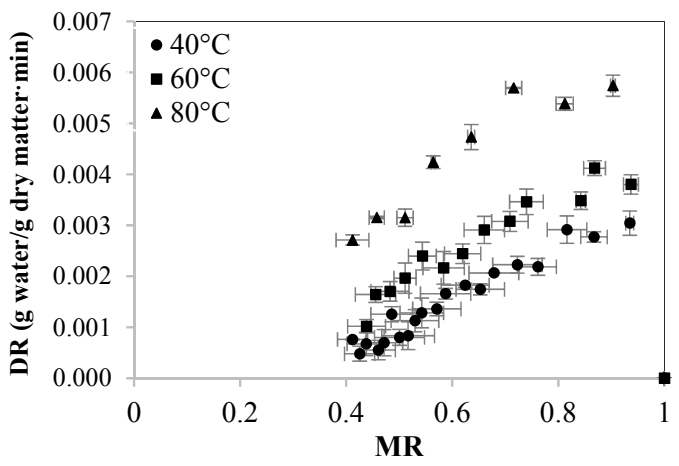

Fig. 4 DR curves of HA-IR drying of the rice bran pellets at the IR intensity of $750 \mathrm{~W} / \mathrm{m}^{2}$.

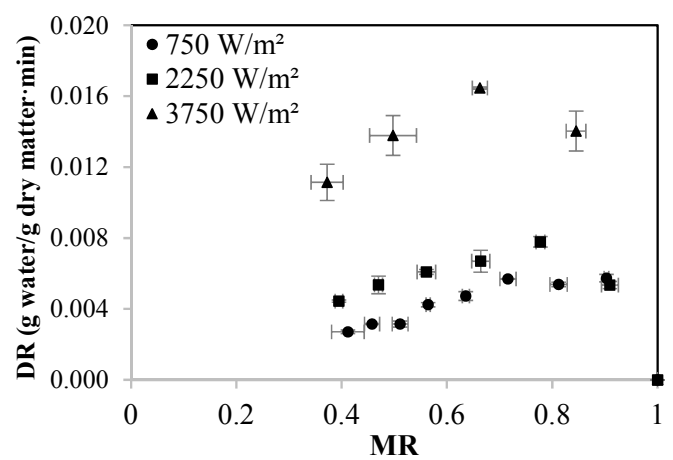

Fig. 5 DR curves of HA-IR drying of the rice bran pellets at the air temperature of $80^{\circ} \mathrm{C}$.
Table 1 Maximum DR (g water/g dry matter $\cdot \min )$ and drying time (min) of HA-IR drying of rice bran pellets.

\begin{tabular}{cccc}
\hline \multirow{2}{*}{$\begin{array}{c}\text { IR intensity } \\
\left(\mathrm{W} / \mathrm{m}^{2}\right)\end{array}$} & \multicolumn{3}{c}{ Air temperature $\left({ }^{\circ} \mathrm{C}\right)$} \\
\cline { 2 - 4 } & 40 & 60 & 80 \\
\hline 750 & $0.0030(54)$ & $0.0041(39)$ & $0.0057(24)$ \\
\hline 2250 & $0.0056(24)$ & $0.0061(21)$ & $0.0078(18)$ \\
\hline 3750 & $0.0133(10)$ & $0.0156(8)$ & $0.0165(8)$ \\
\hline Drying time is presented in parenthesis.
\end{tabular}

\subsection{Effective moisture diffusivity}

$D_{\text {eff }}$ presents the moisture transport property of rice bran pellets during drying in a HA-IR dryer. The effects of air temperature and infrared intensity were also obvious as the $D_{\text {eff }}$ increased with increasing air temperature and infrared intensity (Table 2). It was notable that the $D_{\text {eff }}$ obtained in this study were much greater than the typical range of $D_{\text {eff }}$ of agricultural materials $\left(10^{-11}-10^{-9} \mathrm{~m}^{2} / \mathrm{s}\right)$ [11]. This could be due to the porous structure of the rice bran pellets and the drying technique used in this study which improved the moisture transport property of the material.

Table $2 \mathrm{D}_{\text {eff }} \times 10^{-7}\left(\mathrm{~m}^{2} / \mathrm{s}\right)$ of HA-IR drying of rice bran pellets.

\begin{tabular}{cccc}
\hline \multirow{2}{*}{$\begin{array}{c}\text { IR intensity } \\
\left(\mathrm{W} / \mathrm{m}^{2}\right)\end{array}$} & \multicolumn{3}{c}{ Air temperature $\left({ }^{\circ} \mathrm{C}\right)$} \\
\cline { 2 - 4 } & 40 & 60 & 80 \\
\hline 750 & 0.3103 & 0.5289 & 0.9203 \\
\hline 2250 & 0.9240 & 0.9244 & 1.2293 \\
\hline 3750 & 1.9094 & 2.0146 & 2.7603 \\
\hline
\end{tabular}

\subsection{Quailty evaluation}

The statistical results show that there is no interaction effect between air temperature and IR intensity on oil content and the significant effect on this quality was provided only by the IR intensity as shown in Table 3 $(p<0.05)$. The highest IR intensity resulted in the significant lowest value of oil content. This result conforms to that reported by Trisnawati et al. [12], hot fat due to drying caused reduction of the oil content as the fat components may split into volatile products. However, as compared to the reference, all of the products of this study had higher oil content (Fig. 6).

On the other hand, the interaction effect between air temperature and IR intensity was found on FFA content of the HA-IR dried rice bran pellets $(p<0.05)$. At the fixed levels of IR intensity, increasing air temperature caused reduced formation of FFA in the materials, except at the lowest IR intensity of $750 \mathrm{~W} / \mathrm{m}^{2}$. When keeping the air temperature constant, higher IR intensity seemed to provide significant lower value of FFA, except at the lowest air temperature of $40^{\circ} \mathrm{C}$. As a result, the lowest FFA content was given by HA-IR drying of the rice bran pellets at the highest IR intensity and air temperature of $3750 \mathrm{~W} / \mathrm{m}^{2}$ and $80^{\circ} \mathrm{C}$, respectively. It should be noted that all of the products of this study had lower FFA content than the reference. HA-IR could improve the quality of the dried rice bran pellets. 


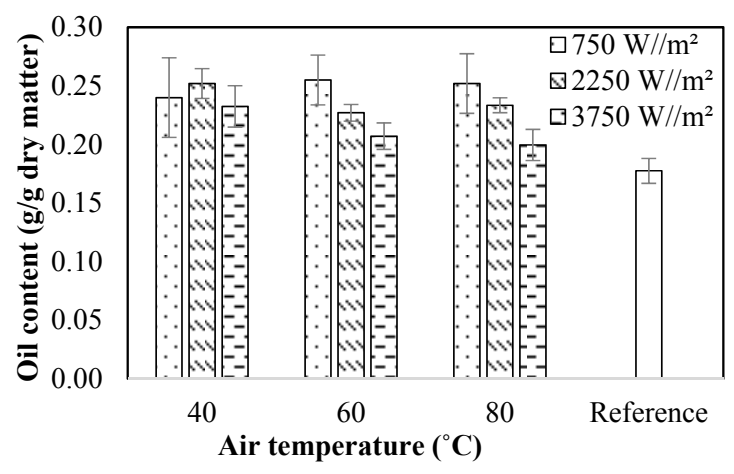

Fig. 6 Oil content of the dried rice bran pellets as compared to the reference.

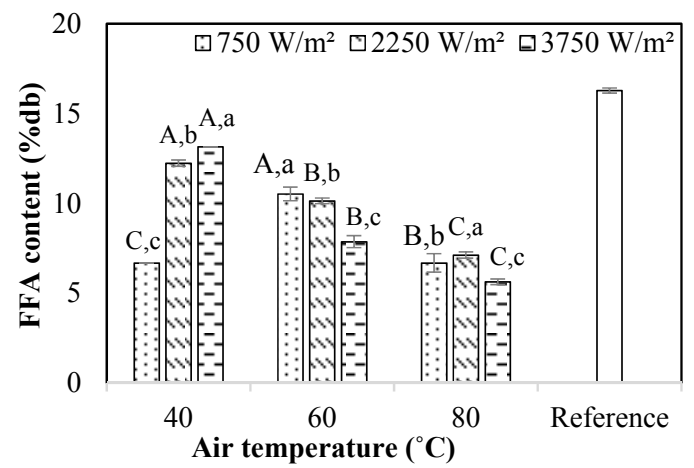

Fig. 7 FFA content of the dried rice bran pellets as compared to the reference.

Uppercases represent the main effect of air temperature at the same IR intensity.

Lowercases represent the main effect of IR intensity at the same air temperature.

Table 3 Oil content of the dried rice bran pellets.

\begin{tabular}{cc}
\hline IR intensity $\left(\mathrm{W} / \mathrm{m}^{2}\right)$ & Oil content $(\mathrm{g} / \mathrm{g}$ dry matter $)$ \\
\hline 750 & $0.249 \pm 0.022 \mathrm{a}$ \\
\hline 2250 & $0.238 \pm 0.014 \mathrm{a}$ \\
\hline 3750 & $0.213 \pm 0.019 \mathrm{~b}$ \\
\hline
\end{tabular}

\section{Conclusions}

Drying characteristics and quality of rice bran pellets undergoing HA-IR drying were determined in this study. IR intensity and air temperature had considerable effects on these parameters. The higher the IR intensity and air temperature were applied, the greater the maximum DR and $\mathrm{D}_{\text {eff }}$ and the shorter drying time were obtained. The greatest maximum DR of $0.0165 \mathrm{~g}$ water/g dry matter and $\mathrm{D}_{\text {eff }}$ of $2.7603 \times 10^{-7} \mathrm{~m}^{2} / \mathrm{s}$ and the shortest drying time of 8 min were provided by HA-IR of the rice bran pellets at the highest IR intensity and air temperature of 3750 $\mathrm{W} / \mathrm{m}^{2}$ and $80^{\circ} \mathrm{C}$. This drying condition also caused the lowest formation of FFA content although the highest IR intensity produced the dried rice bran pellets with the lowest oil content.

\section{References}

1. T. Wang, R. Khir, Z. Pan, Q. Yuan, LWT-Food Science and Technology 78, 281-288 (2017)

2. N. Yilmaz, Food Chemistry 190, 179-185 (2016)
3. S.M. K, H.J. Chung, S.T. Lim, Journal of Cereal Science 60, 243-248 (2014)

4. D.G.P. Kumar, H.U. Hebbar, M.N. Ramesh, LWT 39, 700-705 (2006)

5. K. Ponkham, N. Meeso, S. Soponronnarit, S. Siriamornpun, Food and Bioproducts Processing 90, 155-164 (2012)

6. AOAC, Official methods of analysis (Association of Official Agricultural Chemists, Washington, DC., 1995)

7. C. Contreras, M.E. Martin-Esparza, A. Chiralt, N. Martinez-Navarrete, Journal of Food Engineering 88, 55-64 (2008)

8. A. Ayala-Aponte, L. Serna-Cock, J. LibrerosTriana, C. Prieto, K.D. Scala, DYNA 81, 145-151 (2014)

9. AACC, Approved methods of American Association of Cereal Chemists (The Am. Assoc. Cereal Chem. Inc., St. Paul, MN., 2000)

10. AOCS, Official methods and recommended practices of the American Oil Chemists Society (American Oil Chemists Society, Champaign, 2004)

11. J. Sripinyowanich, A. Noomhorm, Drying Technology 29, 735-748 (2011)

12. W. Trisnawati, K. Suter, K. Suastika, D.N.K. Putra, Food Science and Quality Management 31, 28-36 (2014) 